\title{
Probabilistic Progressive Buckling of Trusses
}

Shantaram S. Pai and Christos C. Chamis

Lewis Research Center

Cleveland, Ohio

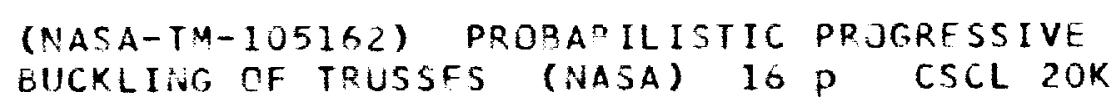

Prepared for the 32nd Structures, Structural Dynamics, and Materials Conference cosponsored by the AIAA, ASME, ASCE, AHS, and ASC Baltimore, Maryland, April 8-10, 1991 



\title{
PROBABILISTIC PROGRESSIVE BUCKLING OF TRUSSES
}

\author{
Shantaram S. Pai and Christos C. Chamis \\ National Aeronautics and Space Administration \\ Lewis Research Center \\ Cleveland, Ohio 44135
}

\begin{abstract}
A three-bay, space, cantilever truss is probabilistically evaluated to describe progressive buckling and truss collapse in view of the numerous uncertainties associated with the structural, material and load variables (primitive variables) that describe the truss. Initially, the truss is deterministically analyzed for member forces and member(s) in which the axial force exceeds the Euler buckling load are identified. These member(s) are then discretized with several intermediate nodes and a probabilistic buckling analysis is performed on the truss to obtain its probabilistic buckling loads and the respective mode shapes. Furthermore, sensitivities associated with the uncertainties in the primitive variables are investigated, margin of safety values for the truss are determined and truss end node displacements are noted. These steps are repeated by sequentially removing buckled member(s) until onset of truss collapse is reached. Results show that this procedure yields an optimum truss configuration for a given loading and for a specified reliability.
\end{abstract}

\section{$\underline{\text { Introduction }}$}

It is customary to evaluate the structural integrity of trusses by using deterministic analysis techniques and appropriate load/ safety factors. Traditionally, these factors are an outcome of many years of analytical, as well as experimental, experience in the areas of structural mechanics/design. Load factors are used to take into account for uncertainties in many different operating conditions including the maximum loads and safety factors are also used to account for unknown effects in analysis assumptions, fabrication tolerances, and material properties.
As an alternative to the deterministic approach, is the Probabilistic Analysis Method (PSAM). ${ }^{1}$ This method formally accounts for various uncertainties in primitive variables (fundamental parameters describing the structural problem) and uses different distributions such as the Weibull, normal, lognormal, etc. to define these uncertainties. Furthermore, PSAM assesses the effects of these uncertainties on the scatter of structural responses (displacements, frequencies, eigenvalues). Thus, PSAM provide a more realistic and systematic way to evaluate structural performance and durability. A part of PSAM is a computer code NESSUS (Numerical Evaluation of Stochastic Structures Under Stress) which provides a choice of solution for static, dynamic, buckling, and nonlinear analysis. ${ }^{2,3}$

In the recent past, NESSUS has been used for the analysis of Space Shuttle Main Engine (SSME) components. Representative examples include a probabilistic assessment of a mistuned bladed disk assembly ${ }^{4}$ and an evaluation of the reliability and risk of a turbine blade under complex service environments. ${ }^{5}$ Furthermore, NESSUS has also been used to computationally simulate and probabilistically evaluate a cantilever truss typical for space type structures ${ }^{6}$ and quantify the uncertainties in the structural responses (displacements, member axial forces, and vibration frequencies). The objective of this paper is to develop a methodology and to perform probabilistic progressive buckling assessment of space type trusses using the NESSUS computer code.

\section{Fundamental Approach and Considerations}

One of the major problems encountered in the analysis of space type trusses is to come 
up with a stable and optimum configuration for given loading conditions and to be able to probabilistically analyze them to take into account the probable uncertainties in the primitive variables typical for space environment conditions. Presently, it is a practice to design these trusses with cross bracings thereby increasing the overall weight of the truss, the cost of fabrication and the effort to deploy in space. Furthermore, the presently available methods/programs do not easily allow us to identify any local instability in any of the internal members of the truss during probabilistic buckling (eigenvalue) analysis and to calculate over all nargins of safety of the truss. Therefore using the NESSUS code, a methodology for the probabilistic progressive buckling is developed as described hereafier.

\section{Finite Element Model}

A three-dimensional, three-bay cantilever truss is computationally simulated using a linear isoparametric beam element based on the Timoshenko beam equations. The element is idealized as a two-noded line segment in three-dimensional space. The cantilever truss is assumed to be made from hollow circular pipe members. The members are made up of wrought aluminum alloy (616-w) with modulus of elasticity (E) equal to $10 \mathrm{Mpsi}$. The ouler and inner radii $\left(r_{o}\right.$ and $\left.r_{i}\right)$ of the tube, are 0.5 and 0.4375 in., respectively. All six degrees of freedom are restrained at the fixed end (left side) nodes. Each bay of the truss is $5 \mathrm{ft}$ wide, $8 \mathrm{ft}$ long, and $6 \mathrm{ft} \mathrm{high} \mathrm{(Fig.} \mathrm{1).}$ The overall length of the truss is $24 \mathrm{ft}$. Six vertical and two longitudinal loads are applied. In addition, twisting moments are applied at the truss-end nodes. The directions of the forces and moments are shown in Fig. 1 and mean values are given in Table I. The applied loads and moments are selected to represent anticipated loading conditions for a typical space truss.

TABLE I. - PRIMITIVE VARIABLES AND UNCERTAINTIES FOR PROBABILISTIC STRUCTURAL ANALYSIS OF A SPACE TRUSS

[Random input data.]

\begin{tabular}{|c|c|c|c|c|}
\hline \multicolumn{2}{|c|}{ Primitive variables } & \multirow{2}{*}{$\begin{array}{c}\begin{array}{c}\text { Distribution } \\
\text { type }\end{array} \\
\text { Normal }\end{array}$} & \multirow{2}{*}{$\begin{array}{c}\begin{array}{l}\text { Mean } \\
\text { value }\end{array} \\
60 \mathrm{in} .\end{array}$} & \multirow{2}{*}{$\begin{array}{c}\begin{array}{c}\text { Scatter, } \\
\pm \text { percentage }\end{array} \\
0.5\end{array}$} \\
\hline Geometry & Width & & & \\
\hline & Length & Normal & $\begin{array}{l}96 \text { in. } \\
192 \text { in. } \\
288 \text { in. }\end{array}$ & $\begin{array}{r}0.1 \\
.1 \\
.1\end{array}$ \\
\hline & Height & Normal & $72 \mathrm{in.}$ & 0.2 \\
\hline Loads & $\begin{array}{l}\text { Vertical } \\
\text { Longitudinal } \\
\text { Twisting moment }\end{array}$ & $\begin{array}{l}\text { Lognormal } \\
\text { Lognormal } \\
\text { Lognormal } \\
\end{array}$ & $\begin{array}{r}20 \mathrm{lb} \\
20 \mathrm{lb} \\
50 \mathrm{lb} \mathrm{in} .\end{array}$ & $\begin{array}{l}6.3 \\
2.5 \\
6.3 \\
\end{array}$ \\
\hline $\begin{array}{l}\text { Malerial } \\
\text { property }\end{array}$ & Modulus & Normal & $10 \mathrm{Mpsi}$ & 7.5 \\
\hline $\begin{array}{l}\text { Tube } \\
\text { radii }\end{array}$ & $\begin{array}{l}\text { Outer radius } \\
\text { Inner radius }\end{array}$ & $\begin{array}{l}\text { Normal } \\
\text { Normal }\end{array}$ & $\begin{array}{l}0.5 \mathrm{in} . \\
0.44 \mathrm{in} .\end{array}$ & $\begin{array}{l}7.5 \\
7.5\end{array}$ \\
\hline
\end{tabular}


Buckling of Columns

In slender columns, a relatively small increase in the axial compressive forces will result only in axial shortening of the member. However, the member suddenly bows out sideways if the load level reaches to a certain critical level. Large deformations caused by increased induced bending moment levels may lead to the collapse of the member. On the other hand, tension members as well as short stocky columns fail when the stress in the member reaches a certain limiting strength of the material. According to Chajes ${ }^{7}$ "...Buckling, however, does not occur as a result of the applied stress reaching a certain predictable strength of the material. Instead, the stress at which buckling occurs depends on a variety of factors, including the dimensions of the nember, the way in which the member is supported, and the properties of the material out of which the member is made...". Chajes also describes the concept of neutral equilibrium which is being used to determine the critical load of a member such that at this load level the member can be in equilibrium both in the straight and in a slightly bent configuration. Furthermore, the Euler load (buckling load or critical load) is the smallest load at which a state of neutral equilibrium is possible or the mernber ceases to be in stable configuration. This above definition of buckling load is used to identify the probable truss members that contribute to the progressive buckling behavior of the cantilever truss.

\section{Probabilistic Model}

The following primitive variables are considered in the probabilistic analysis:

(1) nodal coordinates $(X, Y, Z)$

(2) modulus of elasticity (E)

(3) outer radius of the tube $\left(r_{0}\right)$

(4) inner radius of the tube $\left(r_{i}\right)$

(5) vertical loads (V)
(6) longitudinal loads ( $\mathrm{H}$ )

(7) twisting moments (M)

It is possible that the above primitive variables will vary continuously and simultaneously due to extreme changes in the environment when such trusses are used in upper Farth orbit for space station type structures. The normal distribution is used to represent the uncertainties in $E, r_{0}, r_{i}$, and $X, Y, Z$ coordinates. The applied loads and moments are selected to represent an anticipated loading for a typical space truss. The scatter in these are represented by log-normal distributions. Initially, the NESSUS/FEM (Finite Element Methods) module is used to deterministically analyze the truss for mean values of each of these primitive variables. In the subsequent probabilistic analysis, each primitive variable is perturbed independently and by a different amount. Usually, the perturbed value of the primitive variable is obtained by certain factor of the standard deviation on either side of the mean value. It is important to note that, in the NESSUS code a linear buckling analysis is carried out by making use of the subspace iteration technique to evaluate the probabilistic buckling load. The matrix equation for the buckling (eigenvalue) analysis for a linear elastic structure is as follows:

$$
\left\{[\mathbf{K}]-\lambda\left[\mathrm{K}_{\mathbf{g}}\right]\right\}\{\phi\}=0
$$

In the above equation, $[K]$ is the standard stiffness matrix, $\left[K_{\mathbf{g}}\right]$ is the geometric stiffness matrix, $\lambda$ is the eigenvalue, and $\phi$ are the eigenvectors. Finally, the NESSUS/FPI (Fast Probability Integration) module extracts eigenvalues to calculate a probability distribution of the eigenvalues and to evaluate respective sensitivities associated with the corresponding uncertainties in the primitive variables. The mean, distribution type and percentage variation for each of the primitive variables are given in Table I. 


\section{Probabilistic Progressive Buckling Computational Simulation}

Initially, the truss is deterministically analyzed for member forces and identify the member(s) in which the axial forces exceed the Euler load. These member(s) were then discretized with several intermediate nodes and a probabilistic buckling (eigenvalue) analysis is performed to obtain probabilistic buckling loads and respective buckled shapes. Furthermore, the sensitivity factors representing the impact of uncertainties in the primitive variables on the scatter of response variable (eigenvalue) are evaluated. Finally, any member(s) that have buckled are identified and the probabilistic buckled loads/ moments at each probability level are obtained by multiplying the respective eigenvalues with the applied loads and moments.

In the subsequent analyses the buckled member(s) are removed from the original truss configuration and the above described analysis steps are repeated until onset of collapse state is reached. It is important to note that the mean values of the loads and moments are kept constant and are perturbed around their means during the probabilistic buckling analysis. The truss end node displacements versus the number of members removed are plotted to identify the onset of the truss collapse stale. Finally, the minimum number of members needed to support the applied loads and moments are determined.

\section{Discussion of Results}

\section{Probabilistic Progressive Buckling - First} $\underline{\text { Buckled Member }}$

Figures 2(a) to (f) show the probabilistic progressive buckled mode shapes of the threebay space truss as individual buckled members are sequentially removed from the original configuration until it reaches the onset of collapse. The probabilistic buckling analysis indicated that the first bay front diagonal buckled first, (Fig. 2(b)) and the corresponding probabilistic buckled loads and moments at 0.5 probability are shown for example in Fig. 3. Probabilistic buckled loads and moments at different probability levels can also be obtained. Furthermore, a method of calculating the margin of safety (MOS) for specified probability by using known distributions for applied loads and moments and corresponding cumulative distribution function curves obtained from PSAM are shown in Fig. 4. The sensitivity factors from Fig. 5 suggest that the scatter in the bay length parameter (Y-coordinate) had the highest impact on the probabilistic distribution of the buckling load followed by the bay height (Z-coordinate), bay width (X-coordinate), vertical and longitudinal loads and finally twisting moments. Any slight variation in spacial (geometry) variables has a direct effect on the overall length of the members and thereby alters many terms in the stiffness matrix containing the length parameter. Finally, this has a definite affect on the probabilistic buckling loads which has been clearly observed in the above discussed results. However, it is important to note that even comparatively large variations in both member modulus $(E)$ and area $\left(r_{0}\right.$ and $r_{i}$ ) (see Table I) had very negligible impact. Similar conclusions can also be drawn for the probabilistic member force in the first buckled member (see Fig. 6). The variation in the resistance (mean area $x$ mean yield strength) of the member was assumed to have a Weibull distribution and is shown in Fig. 7. MOS calculations for strength exceedence using distribution curves for probabilistic member force and resistance as well as probabilistic buckling load and resistance indicate that the buckled member did satisfy the strength criteria condition. Therefore, it can be concluded from Figs. 4 and 7 that the member buckled when its axial force exceeded the Euler buckling load and when the stress due to this load did not exceed the failure criteria.

Probabilistic Progressive Buckling Second/Third/Fourth Buckled Members

As described in the previous section, the deterministic analysis followed by the 
probabilistic analysis was performed with sequential removal of the first, second, third, and fourth buckled member from the truss and the probabilistic buckled loads and moments, sensitivity factors, and MOS values for stress were obtained. When the second member was buckled (see Fig. 2(c)) the comparable results as shown in Figs. 4 to 7 are described in Figs. 8 to 11 . For these truss configurations the MOS value decreased from 3.53 to 2.53 . The similar details of the truss with the third buckled (see Fig. 2(d)) are given in Figs. 12 to 15 . According to Fig. 13, the MOS value further decreased to 1.62. Similarly, Figs. 16 to 19 give comparable results of the truss when the fourth member was buckled (see Fig. 2(e)). It is important to note from Figs. 18 and 19 that, the scatter in the bay height had much higher impact than scatter in both bay width and length on both the probabilistic buckling loads/moments and buckled member force. Finally, the details of the onset of collapse state of the truss (Fig. 2(I)) are shown in Figs. 20 to 22. When all the four buckled members were removed, the MOS value was equal to -3.75 which indicates that the onset of collapse was reached (Fig. 21). Furthermore, the probabilistic buckling loads/ moments at 0.001 probability were equal to maximum applied loads/moments with assumed distributions (see Fig. 20). In addition, at the collapse state the uncertainties in both the bay length and bay height had sufficiently high impact on the probabilistic buckling loads/moment distributions (see Fig. 22). In the above discussed various truss configurations, the uncertainties in the vertical loads had consistently the same impact on buckling loads/moment, where as member modulus and area had negligible impact.

\section{$\underline{\text { Probabilistic Truss End Node Displacements }}$}

The truss end node displacements (lateral, longitudinal, and lateral) were also calculated during each of above mentioned deterministic analyses for each truss configuration and are shown in Fig. 23. It is clear that there is not considerable cliange in either lateral or longitudinal displacement as each buckled member was sequentially removed. However, the truss end node vertical displacement gradually increased up to the truss configuration with three buckled members removed and suddenly increased very rapidly when the fourth buckled member was removed giving an indication of unbounded displacement growth which suggests that the truss had reached the onset of its collapse state. This is due to the fact that the total vertical loads are six times higher than total longitudinal luads and the perturbations in the vertical loads are higher than that of twisting moments. Figures 24 and 25, respectively, show the relationships between the applied vertical loads and probabilistic buckling loads as well as probabilistic buckling loads and MOS values. The optimum truss configuration was reached with the forth buckled member removed whereby the probabilistic buckling load was equal to the applied vertical load at 0.001 probability level (see Fig. 24). Similar conclusions can also be made for longitudinal loads and twisting moments. In addition, there is a gradual decrease in the MOS values as buckled members were sequentially removed and reached a zero value when the optimum truss configuration was reached (see Fig. 25). Similar conclusions can also be made for longitudinal loads and twisting moments.

\section{Probabilistic Buckling Including Initial Eccentricity}

In the above discussed probabilistic progressive buckling methodology, all the members were assumed to be initially perfectly straight and the buckled members were sequentially removed with the assumption that once the member buckled it would yield and could not resist any additional loading and thereby would not contribute to the overall stiffness of the truss. In order to verify this assumption, the maximum eccentricity at which the yielding in the member (first bay front diagonal) will take place due to the combined effects of axial and in-plane bending moments was calculated. Furthermore, this 
member was modeled to depict the buckled configuration of the member at which yielding will take place, using a parabolic distribution for the above calculated eccentricity (see Fig. 26). The deterministic and subsequent probabilistic buckling analyses indicate, respectively, that the probabilistic buckling loads and moments did not change significantly from the original analysis (see Fig. 3) and the first bay rear diagonal has buckled (see Fig. 27). However, as seen from Figs. 5 and 28 for probabilistic buckling loads and from Figs. 6 and 29 for probabilistic member forces, the sensitivity factors show some changes especially the variations in bay width has the most dominant impact on both probabilistic buckling loads and moments (see Figs. 28 and 29). This is due the fact that member buckles in the plane perpendicular to the direction of the loading. Nevertheless, it is important to note that the scatter in the spacial location accentuates the sensitivities of the bay length/width/height on the probabilistic load and diminishes that of vertical load. Once again the variations in the member modulus and area have very negligible impact. These results justify the sequential removal of the buckled members during progressive buckling.

\section{Conclusions}

The computational simulation of probabilistic progressive buckling of a space type truss is demonstrated using the NESSUS computer code and step-by-step procedure is outlined. The methodology for onset of truss collapse is established. The progressive buckled mode shapes are obtained and sensitivities associated with the uncertainties in the primitive variables are evaluated. The safety margins are determined and the optimum truss is obtained for the given loading condition. The results indicate that: (1) probabilistic buckling loads and margin of safety values decrease as buckled member(s) are sequentially removed; (2) the scatter in truss geometry (bay length/width/height) and vertical loads have considerable impact on the probability of the the buckled load; (3) the member modulus and area parameters have negligible impact; and (4) initial eccentrics have negligible influence on the probabilistic buckling load but may influence the sensitivities. Collectively the results demonstrate that the probability of collapse of space-type trusses can be reliably assessed by the procedure described herein.

\section{$\underline{\text { References }}$}

1. Chamis, C.C.: Probabilistic Structural Analysis Methods for Critical SSME Propulsion Components. Space System Technology Conference, AIAA, New York, 1986, pp. 133-144.

2. Dias, J.B.; Nagtegaal, J.C.; and Nakazawa, S.: Iterative Perturbation Algorithms in Probabilistic Finite Analysis. Computational Mechanics of Probabilistic and Reliability Analysis, W.K. Liu and Belytschko, eds., ELME PRESS International, Lausanne, Switzerland, 1989, pp. 211-230.

3. Wu, Y.T.: Demonstration of New, Fast Probability Integration Method for Reliability Analysis. Advances in Aerospace Structural Analysis, O.M. Burnside and C.H. Parr, eds., ASME, 1985, pp. 63-73.

4. Shah, A.R.; Nagpal, V.K.; and Chamis, C.C.: Probabilistic Analysis of Bladed Turbine Disks and the Effect of Mistuning. 31st Structures, Structural Dynamics and Materials Conference, Part 2, AIAA, 1990, pp. 1033-1038. (Also, NASA TM-102564.)

5. Shiao, M.C.; and Chamis, C.C.: A Methodology for Evaluating the Reliability and Risk of Structures under Complex Service Environments. 31st Structures, Structural Dynamics and Materials Conference, Part 2, AIAA, 1990, pp. 1070-1080. (Also, NASA TM-103244.) 
6. Pai, S.S.: Probabilistic Structural Analysis of a Truss Typical for Space Station. NASA TM-103277, 1990.
7. Chajes, A.: Principles of Structural Stability Theory. Prentice-Hall, 1974.

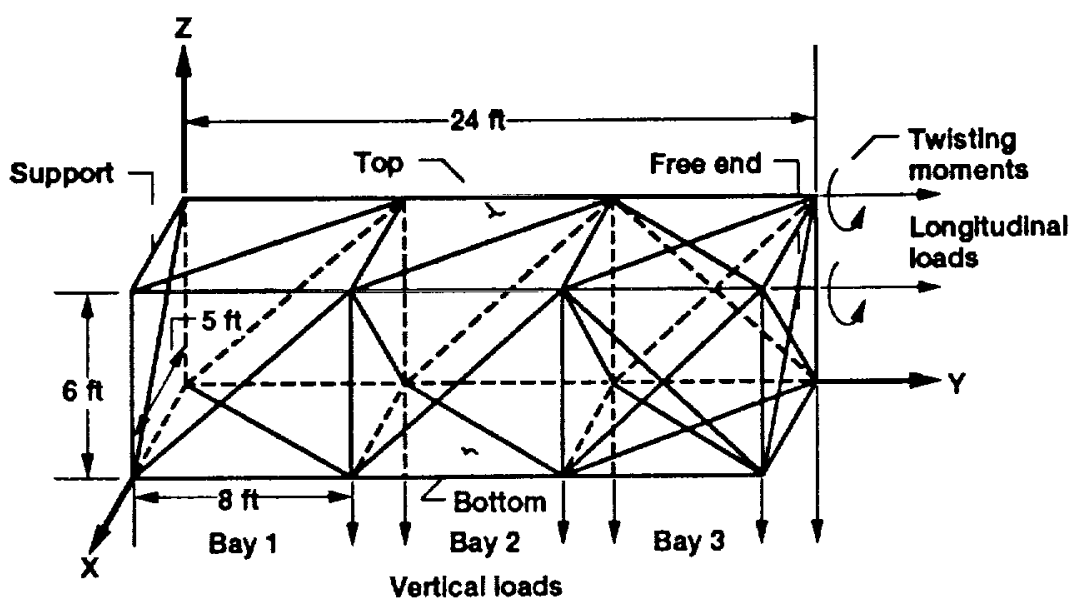

Figure 1.-Solar array panels mast - typlcal truss. 


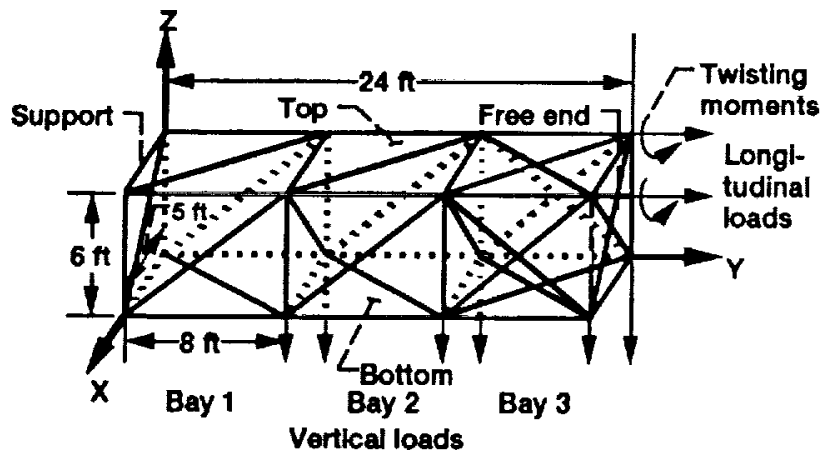

(a).

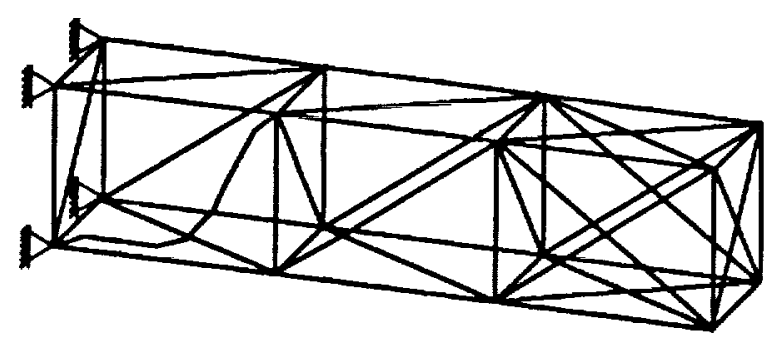

(b).

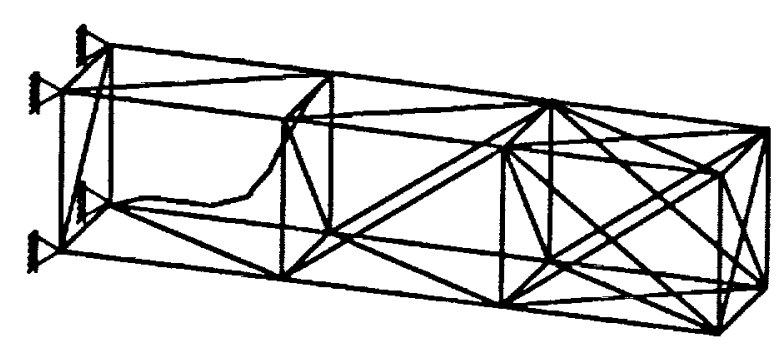

(c).

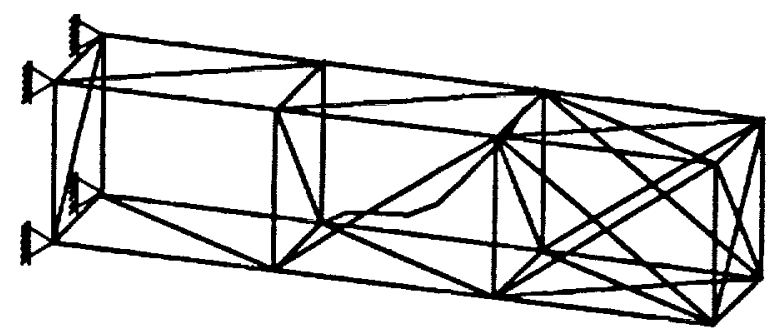

(d).

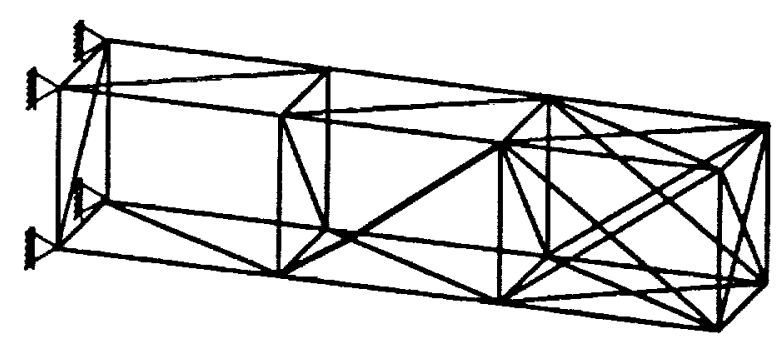

(e).

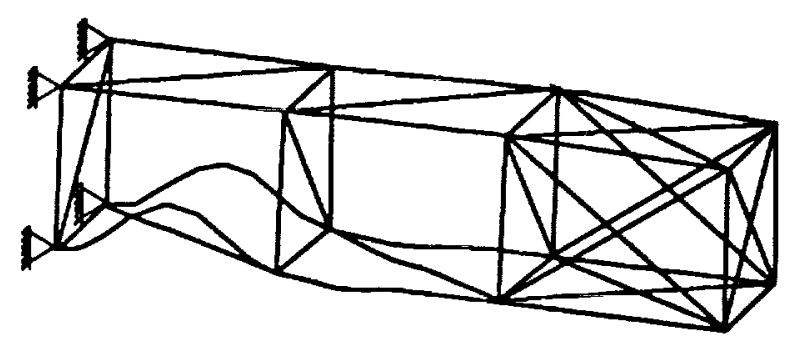

(f).

Figure 2.-Probabllistic progressive buckling as buckled members sequentially removed.

First buckled member - First bay front dlagonal

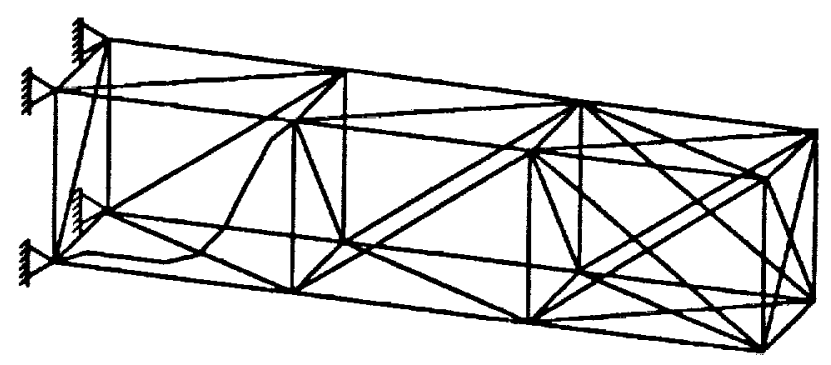

Probabilistic buckled loadina condition (0.5 Probs)

$\begin{array}{ll}\text { Vertical load } & 782 \mathrm{lb} \\ \text { Longltudinal load } & 260 \mathrm{lb} \\ \text { Twisting moment } & 651 \mathrm{lb} \text {-in. }\end{array}$

Figure 3.-Probablistic progressive buckling. 


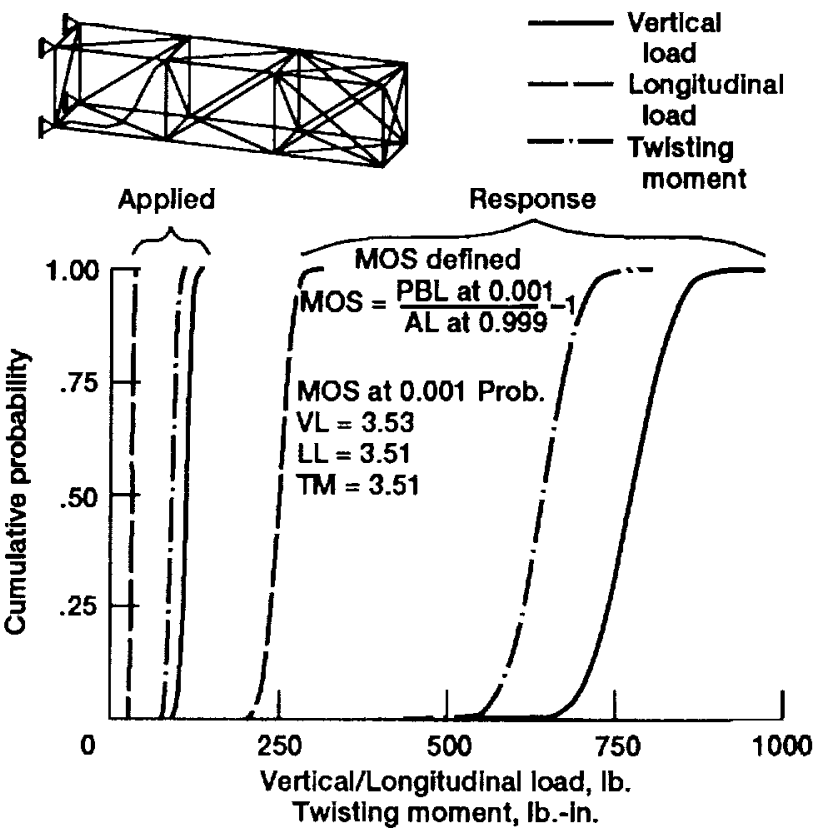

Figure 4.-Probabilistic buckling load.

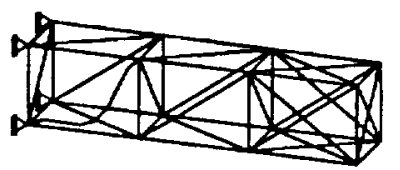

Vertical load $\quad 782 \mathrm{lb}$

Longltudinal load $260 \mathrm{lb}$ Twisting moment $651 \mathrm{lb}$-in.

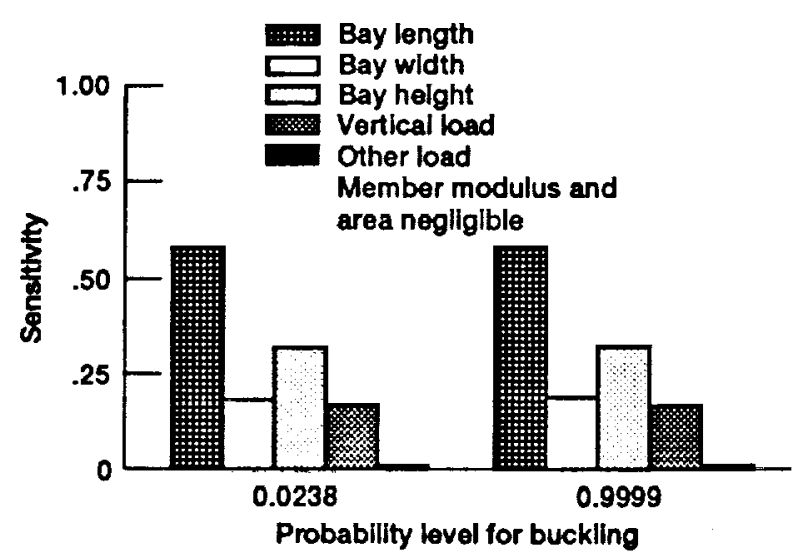

Figure 6.-Probabllistic member force sensltivlty.

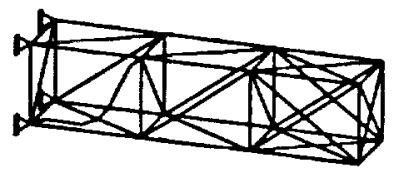

Vertical load $782 \mathrm{lb}$ Longitudinal load $260 \mathrm{lb}$ Twisting moment $651 \mathrm{lb}$-in.

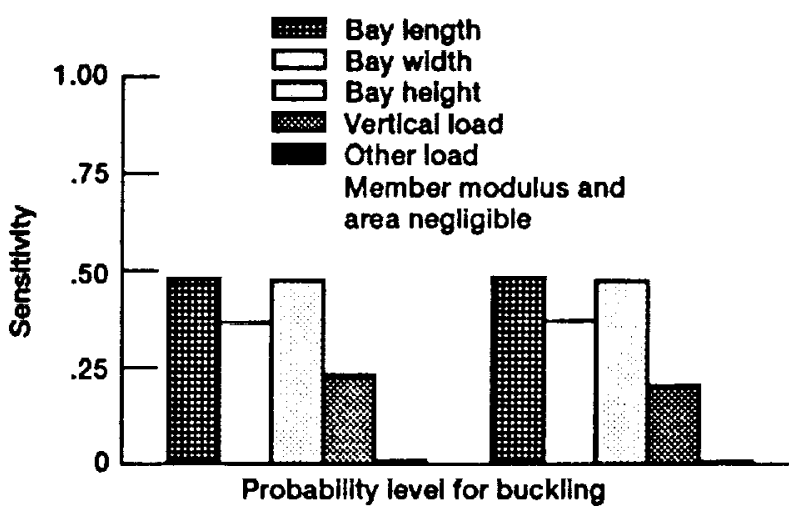

Figure 5.-Probabilistic buckling load sensitivlty.
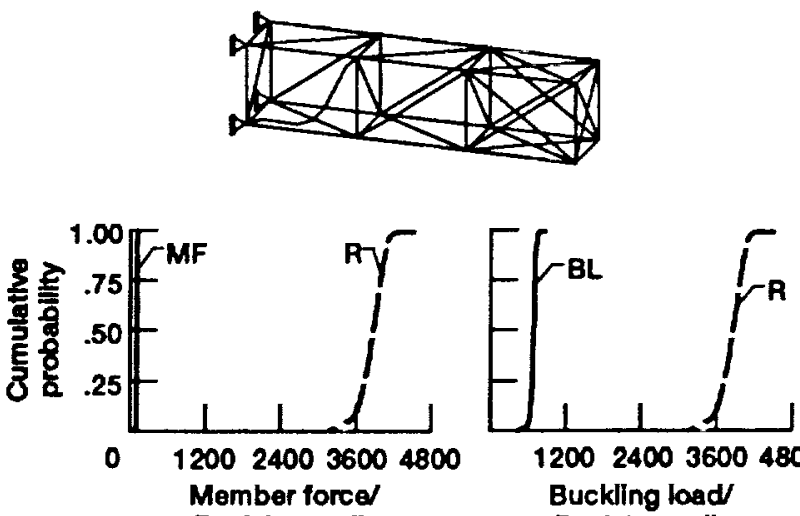

1200240036004800

Buckling load/

Resistance,lb

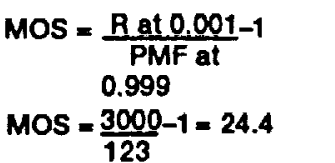

MOS $=\frac{R \text { at } 0.001}{P B L}-1$ 0.999

MOS $=3000-1=3.75$ 801

Figure 7.-Probablity of strength exceedence for first bay front diagonal). 
First buckled member removed - First bay front dlagonal Second bucled member

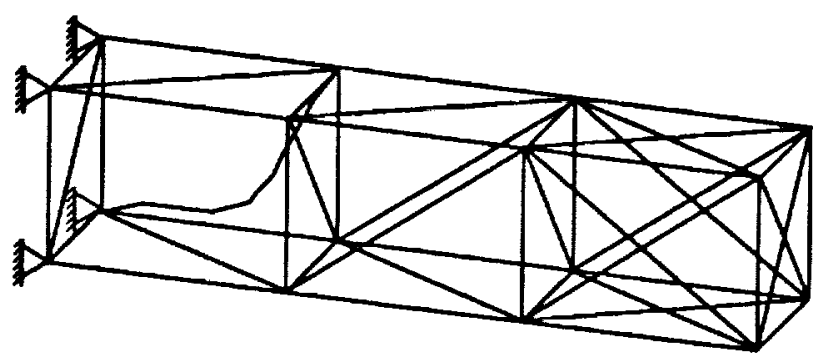

Rrobabilistic buckled loading condition $(0.5$ Prob)

Vertical load

$586 \mathrm{lb}$

Longltudinal load $196 \mathrm{lb}$

Twisting moment $488 \mathrm{lb}$-in.

Figure 8.-Probabilistic progressive buckling.

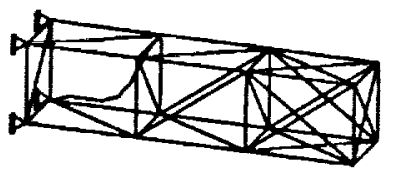

Vertical load $\quad 586 \mathrm{lb}$ Longitudinal load $196 \mathrm{lb}$ Twisting moment $488 \mathrm{lb}$-in.

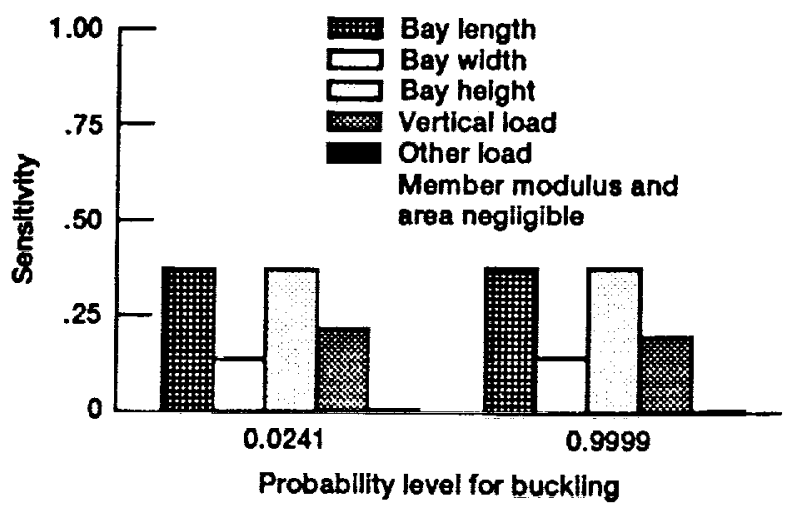

Figure 10.-Probabilistic buckling load sensitivity.
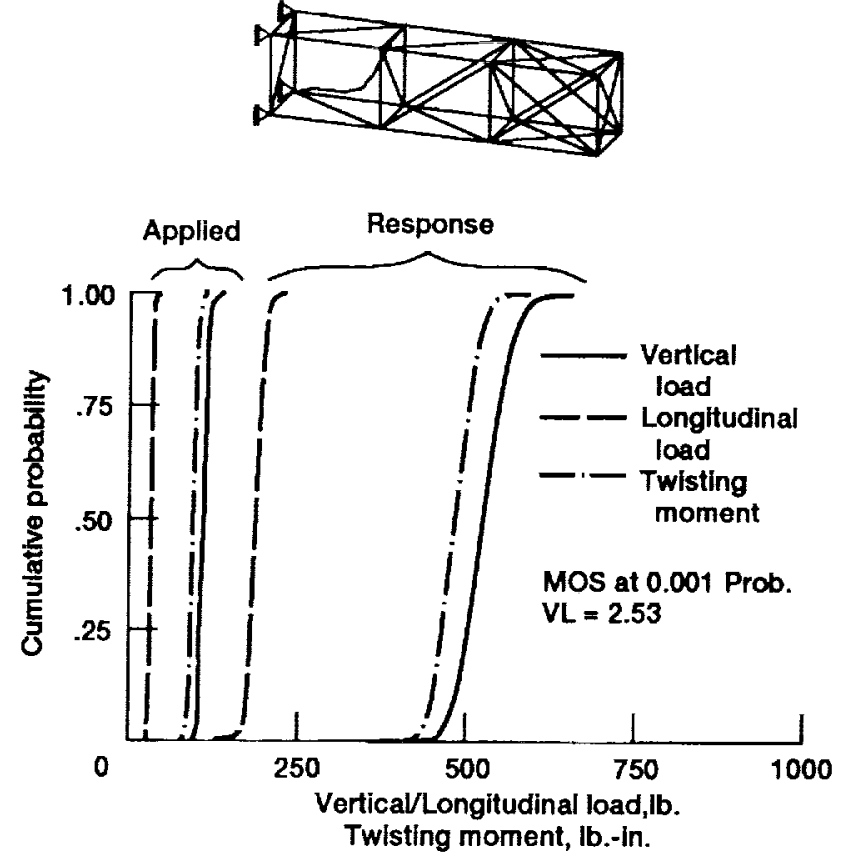

Figure 9.-Probabilistic buckling load.

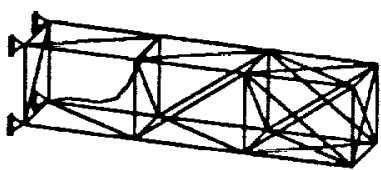

Vertical load $\quad 586 \mathrm{lb}$ Longitudinal load $196 \mathrm{lb}$ Twisting moment $488 \mathrm{lb}-\mathrm{ln}$.

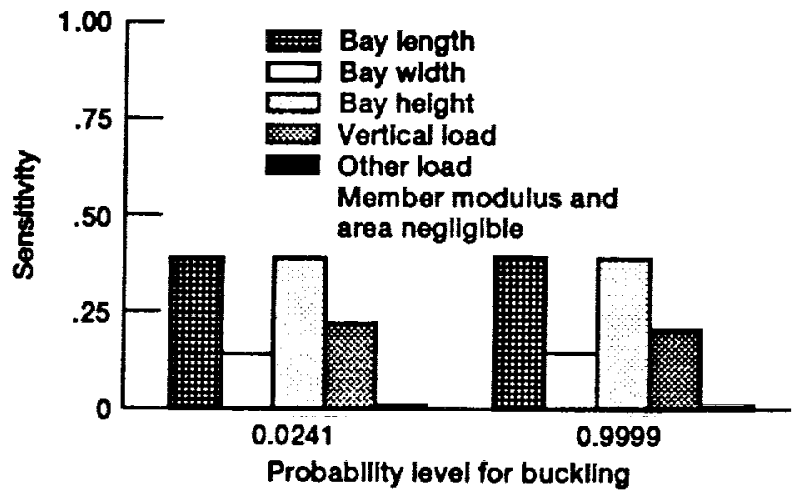

Figure 11.-Probabilistic member force sensitivity. 
First buckled member removed - First bay front dlagonal Second buckled member removed - First bay rear dlagonal Third buckled member - Second bay rear diagonal

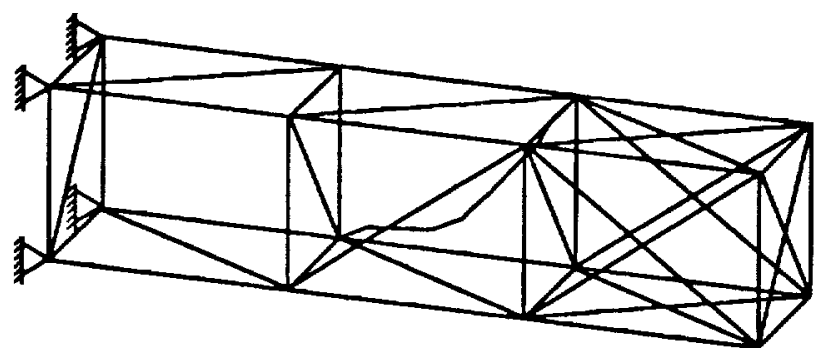

Probabillstic buckled leading condition (0.5. Probu)

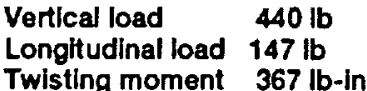

Figure 12.-Probabilistic progressive buckling.

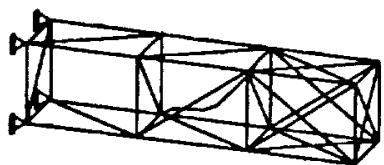

Vertical load $\quad \mathbf{4 4 0} \mathrm{lb}$

Longltudinal load $147 \mathrm{lb}$

Twlsting moment $367 \mathrm{lb}$-in.

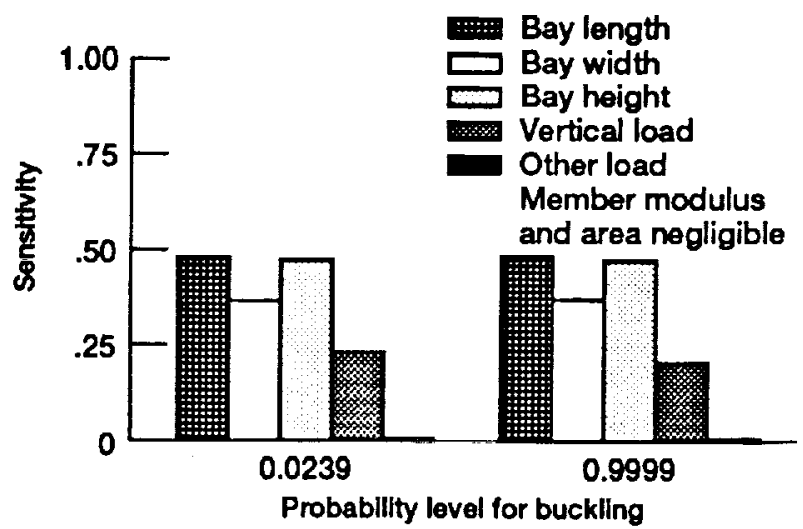

Figure 14.-Probabllistic buckling load sensitivity.
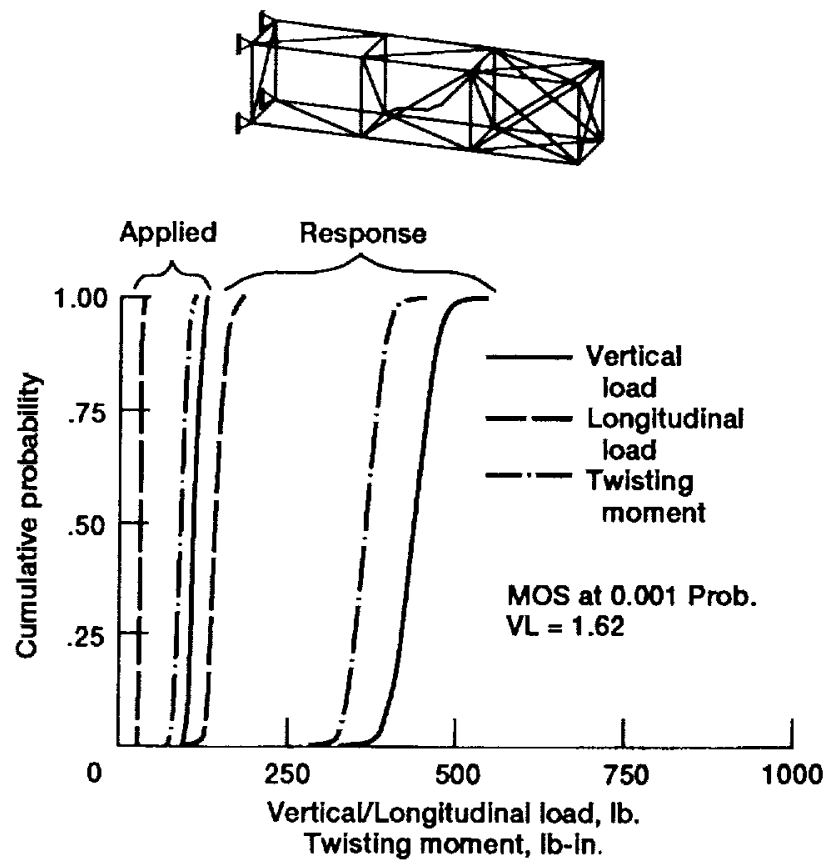

Figure 13.-Probabilistic buckling load.

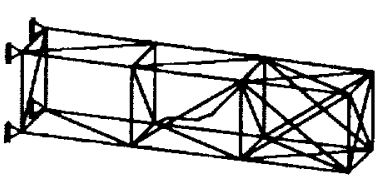

Vertical load $\quad 440 \mathrm{lb}$ Longitudinal load $147 \mathrm{lb}$

Twisting moment $367 \mathrm{lb}-\mathrm{ln}$.

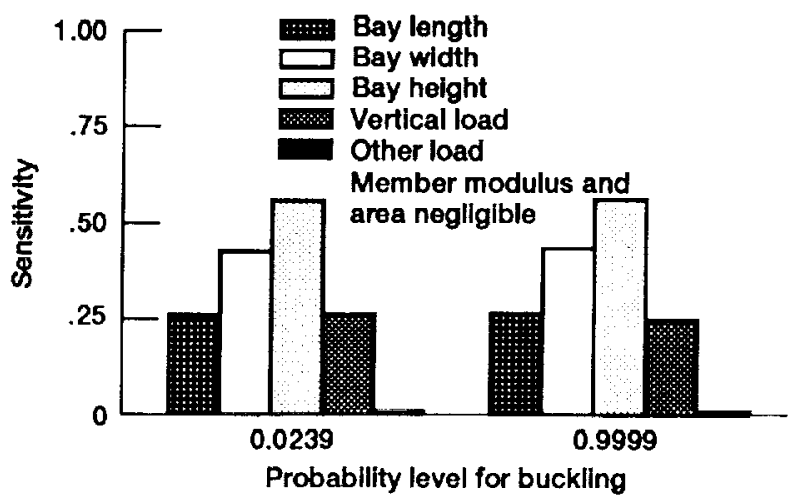

Figure 15._Probabllistic member force sensitivity. 
First buckled member removed - First bay front dlagonal Second buckled member removed - First bay rear diagonal Third buckled member removed - Second bay rear dlagonal Fourth buckled member - Second bay front dlagonal

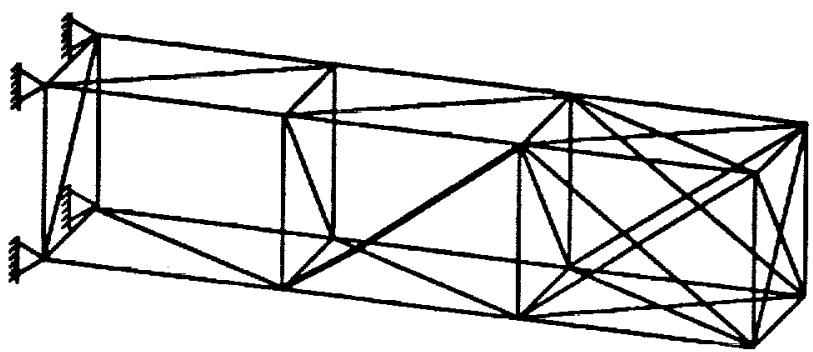

Probabllistle buckled loading condition (0.5 Prob)

Vertical load

$233 \mathrm{lb}$

Longltudinal load $\mathbf{7 8} \mathrm{lb}$

Twisting moment $194 \mathrm{lb}$-in.

Flgure 16.-Probabilistic progressive buckling.

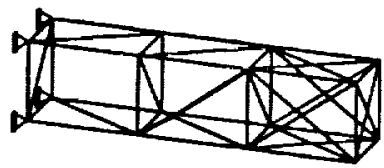

Vertical load $233 \mathrm{lb}$ Longltudinal loed $78 \mathrm{lb}$ Twisting moment $194 \mathrm{lb}-\mathrm{ln}$.

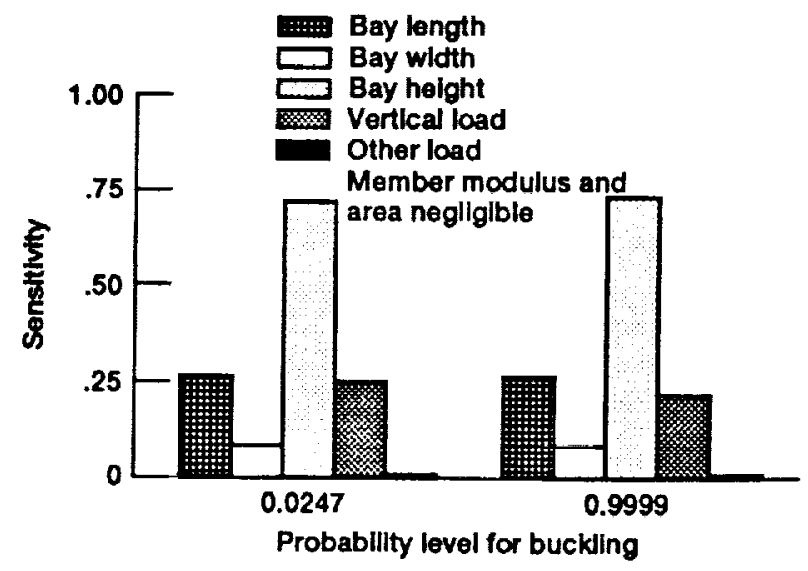

Flgure 18.-Probabilistlc buckling load senslivity.
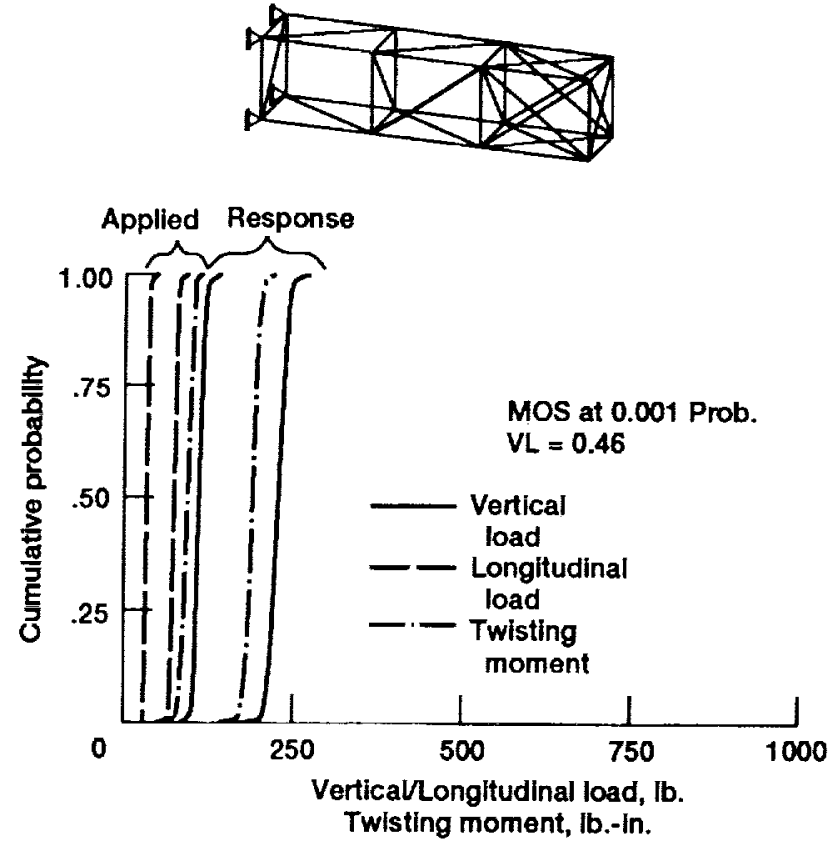

Flgure 17.-Probabilistic buckling load.

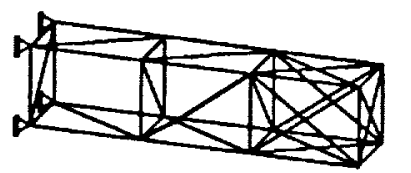

Vertical load $233 \mathrm{lb}$

Longitudinal load $78 \mathrm{lb}$

Twisting moment $194 \mathrm{lb}$-in.

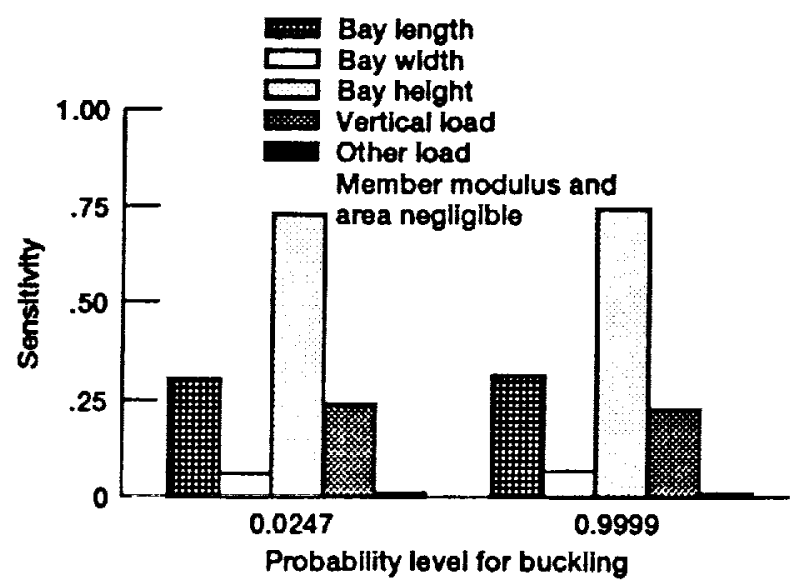

Figure 19.-Probablistic member force sensitivity. 
First buckled member removed - First bay front dlagonal Second buckled member removed - First bay roar dlagonal Third buckled member removed - Second bay rear dlagonal Fourth buckled member removed - Second bay front diagonal

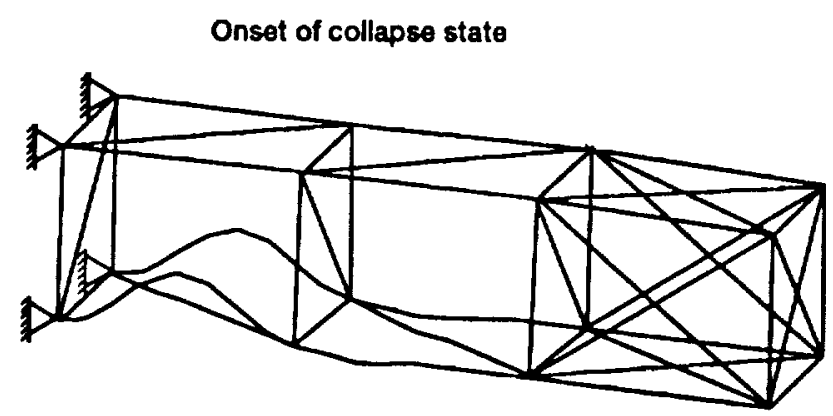

Probabillstic buckled loadina condition (0.001 Prob)

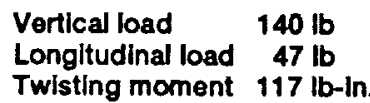

Figure 20.-Probabillstic progressive buckllng.

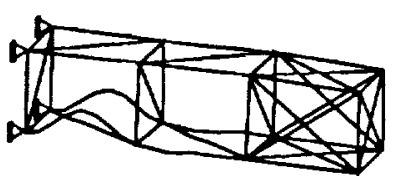

Vertical load $\quad 140 \mathrm{lb}$

Longltudinal load $47 \mathrm{lb}$

Tw/sting moment $117 \mathrm{lb}$-in.

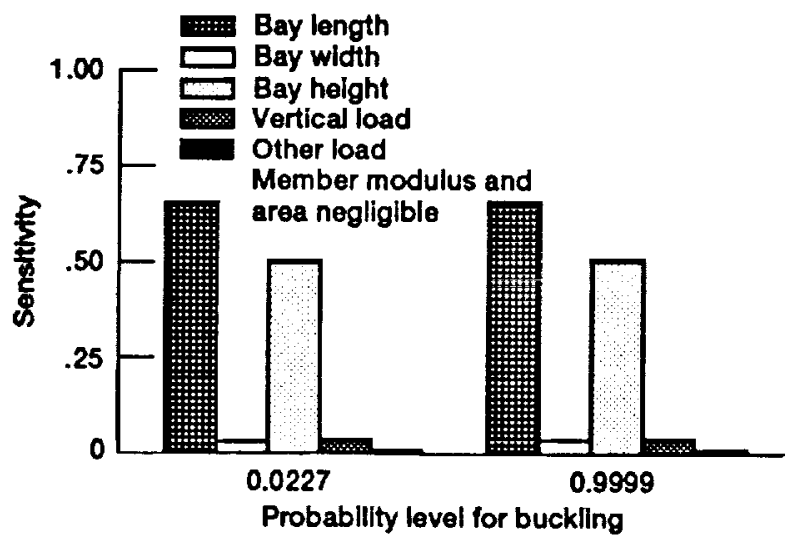

Figure 22.-Probablistic buckling load sensitivity.
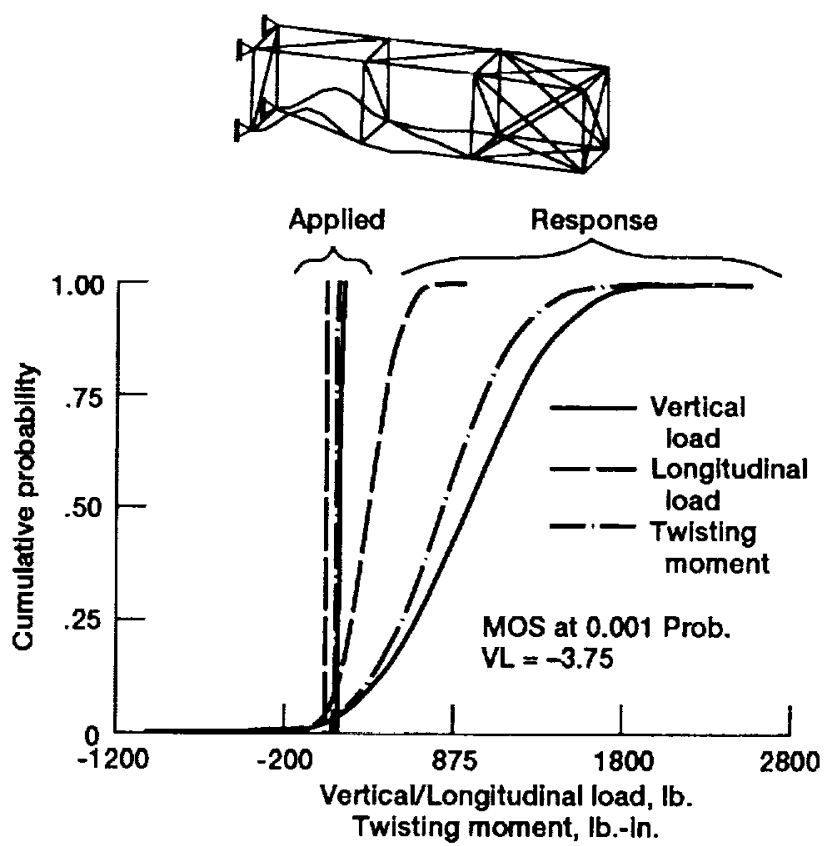

Figure 21._Probabilistic buckling load.

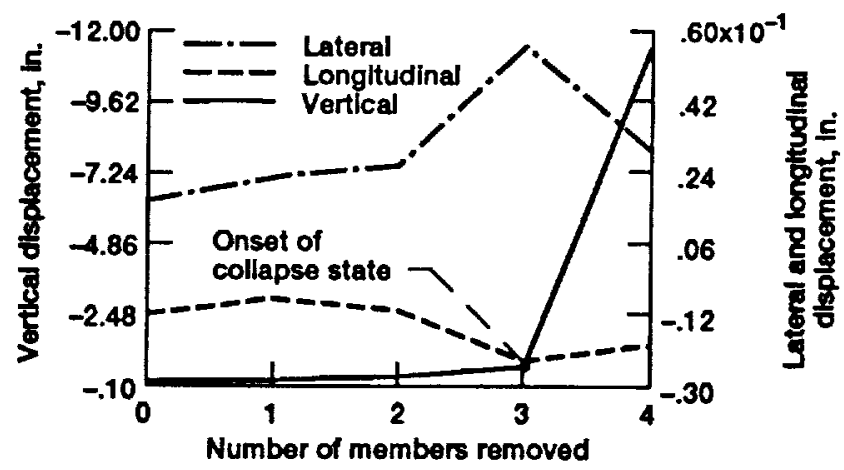

Figure 23.-Progresslve buckling leading to structural collapse as Indicated by unbounded displacement. 


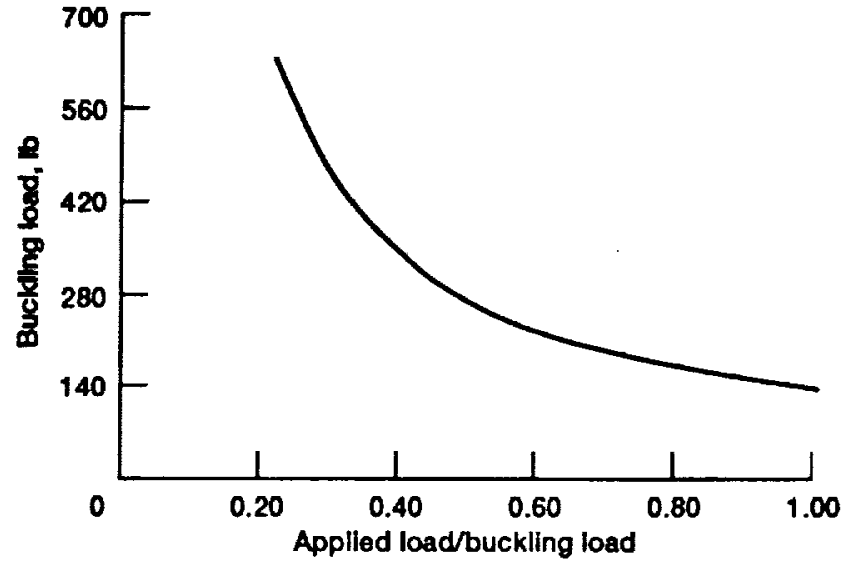

Figure 24.-Buckling load vs applled load/buckling load at 0.001 probablilty.

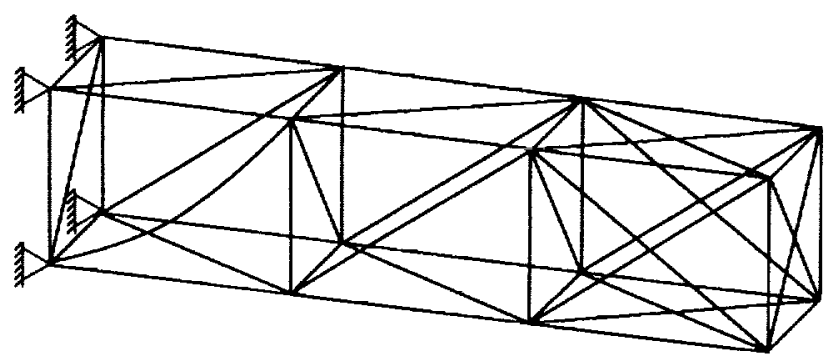

Figure 26. -First bay front diagonal with initial eccentricity.

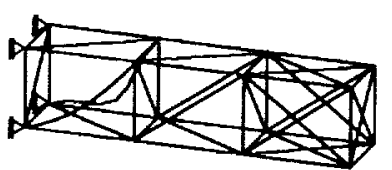

Vertical load $762 \mathrm{lb}$

Longltudinal load $254 \mathrm{lb}$

Twisting moment $635 \mathrm{lb}-\mathrm{In}$.

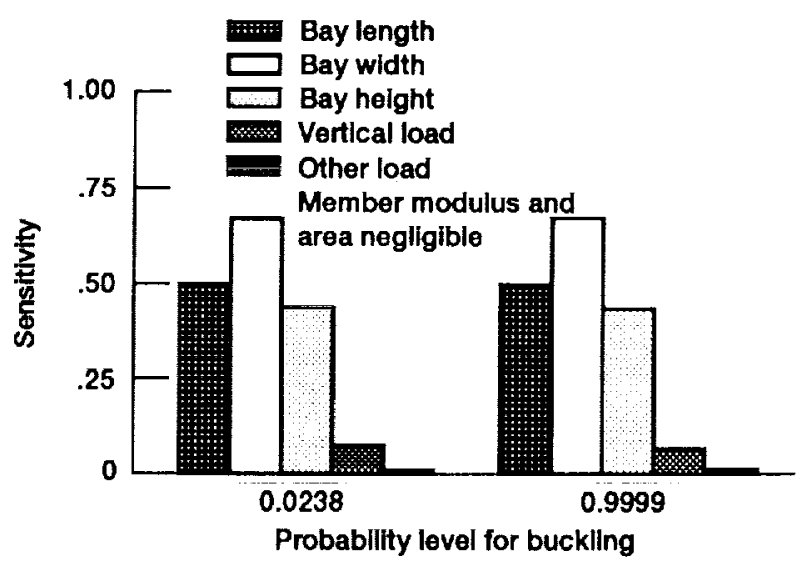

Figure 28.-Probabilistic buckling load sensitivity.

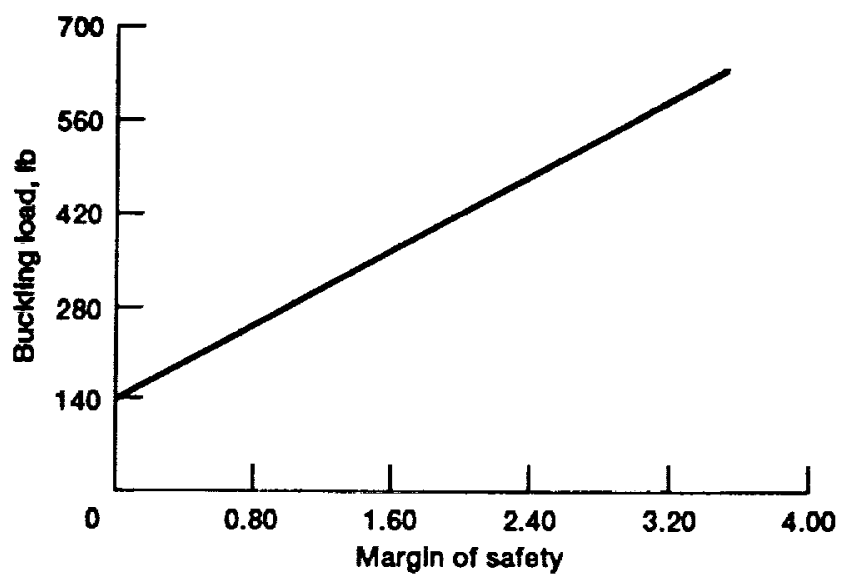

Figure 25.-Buckling load vs margin of safety at 0.001 probablity.

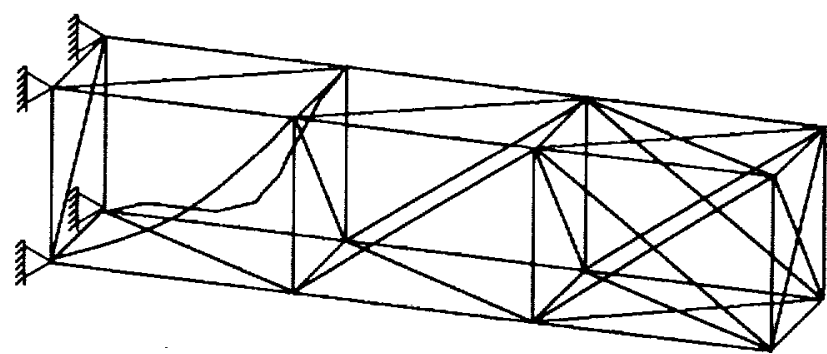

Probabilistic bucked loading condition $(0.5$ prob.)

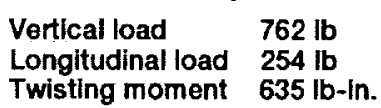

Figure 27.-Probabilistic buckling-first bay rear diagonal buckled.

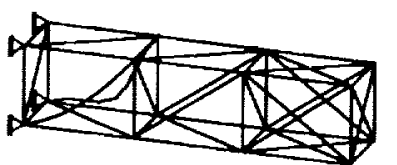

Vertical load $\quad 762 \mathrm{lb}$

Longltudinal load $254 \mathrm{lb}$

Twisting moment $635 \mathrm{lb}$-in.

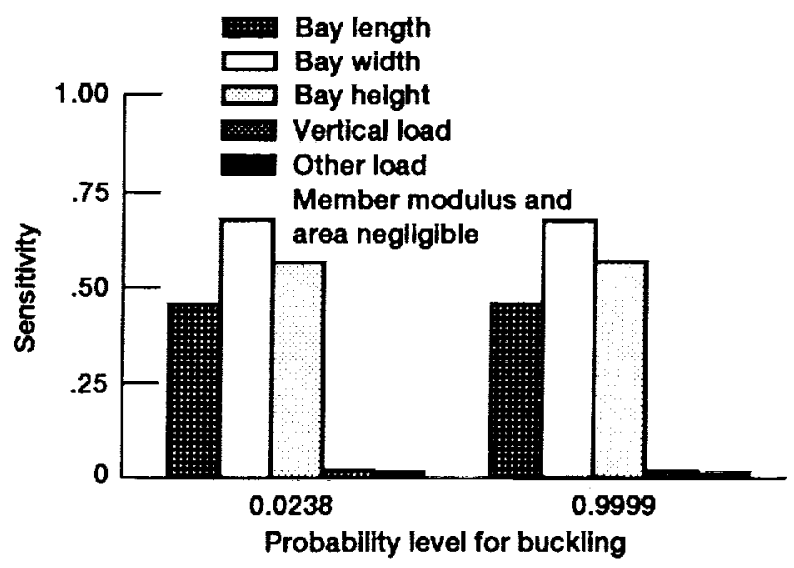

Figure 29.-Probabilistic member force sensitivity. 


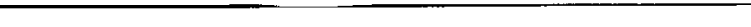




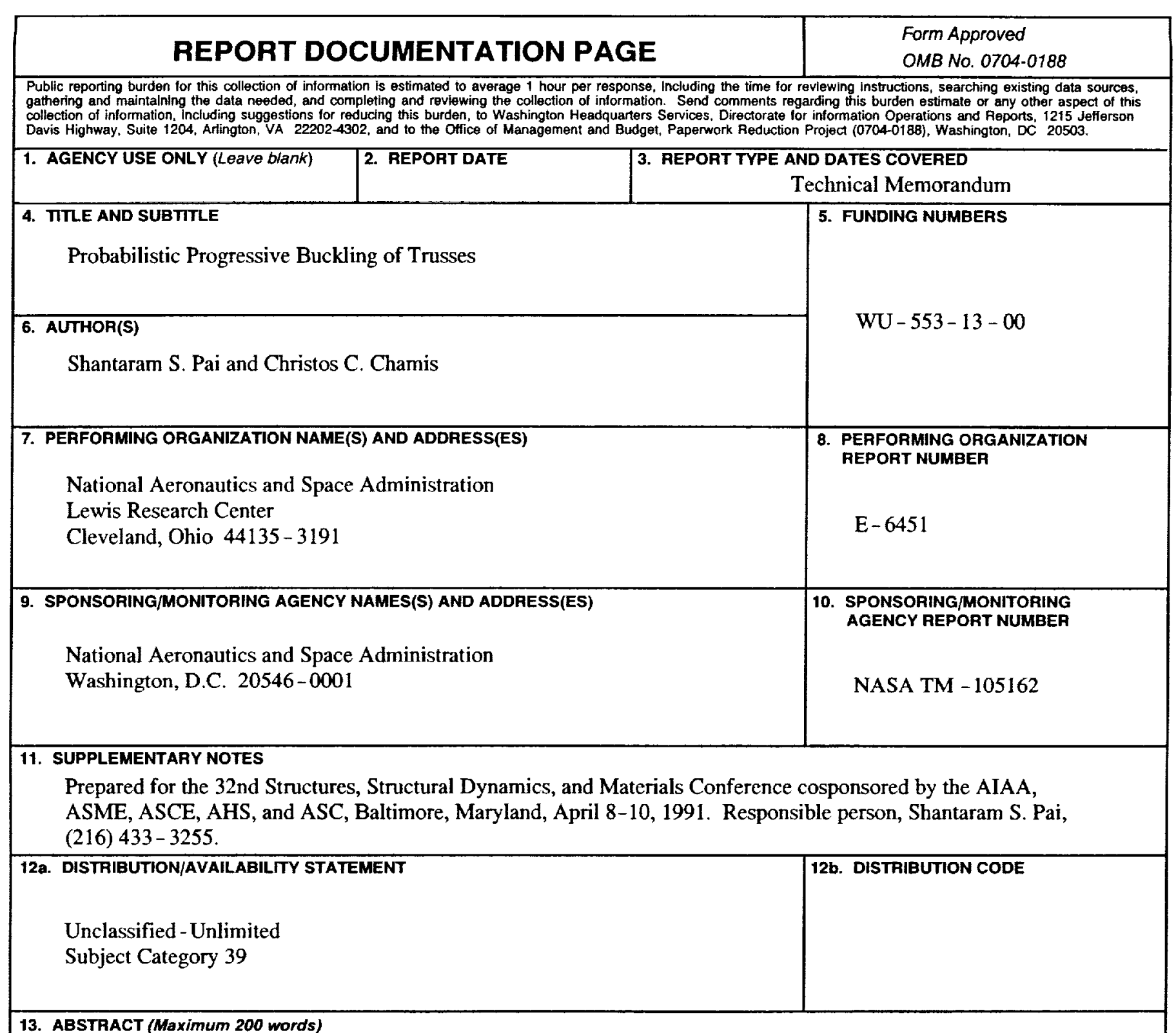

A three-bay, space, cantilever truss is probabilistically evaluated to describe progressive buckling and truss collapse in view of the numerous uncertainties associated with the structural, material and load variables (primitive variables) that describe the truss. Initially, the truss is deterministically analyzed for member forces, and member(s) in which the axial force exceeds the Euler buckling load are identified. These member(s) are then discretized with several intermediate nodes and a probabilistic buckling analysis is performed on the truss to obtain its probabilistic buckling loads and the respective mode shapes. Furthermore, sensitivities associated with the uncertainties in the primitive variables are investigated, margin of safety values for the truss are determined and truss end node displacements are noted. These steps are repeated by sequentially removing buckled member(s) until onset of truss collapse is reached. Results show that this procedure yields an optimum truss configuration for a given loading and for a specified reliability.

\begin{tabular}{|c|c|c|c|}
\hline \multirow{2}{*}{\multicolumn{3}{|c|}{$\begin{array}{l}\text { 14. SUBJECT TERMS } \\
\text { Progressive buckling; Margin of safety; Uncertainties; Fast-probability integration; } \\
\text { Probabilistic theory; Geometry; Materials; Eccentricity; Finite element method; } \\
\text { Statistical distributions }\end{array}$}} & $\begin{array}{l}\text { 15. NUMBER OF PAGES } \\
16\end{array}$ \\
\hline & & & $\begin{array}{r}\text { 16. PRICE CODE } \\
\text { A03 }\end{array}$ \\
\hline $\begin{array}{l}\text { 17. SECURITY CLASSIFICATION } \\
\text { OF REPORT } \\
\text { Unclassified }\end{array}$ & $\begin{array}{l}\text { 18. SECURITY CLASSIFICATION } \\
\text { OF THIS PAGE } \\
\text { Unclassified }\end{array}$ & $\begin{array}{l}\text { 19. SECURTY CLASSIFICATION } \\
\text { OF ABSTRACT } \\
\text { Unclassified }\end{array}$ & 20. LIMITATION OF ABSTRACT \\
\hline
\end{tabular}

